\title{
Qualidade industrial e maturação de frutos de laranjeiras-doce em Rio Branco, Acre*
}

\author{
Paulo Márcio Beber ${ }^{1}$, Virgínia de Souza Álvares² \& Jorge Ferreira Kusdra ${ }^{3}$ \\ RESUMO
}

Embora a laranjeira seja a segunda frutífera mais cultivada no Estado do Acre, atrás apenas da bananeira, a produção não atende o mercado local, dependendo da importação de outros estados, principalmente pela falta de genótipos adaptados à região. Objetivou-se com este trabalho avaliar genótipos de laranjeira-doce, enxertadas sobre limoeiro Cravo, em relação à produção e características físico-químicas dos frutos em diferentes estádios de maturação em Rio Branco, Acre. Realizou-se um experimento com delineamento inteiramente casualizado em arranjo de parcelas subdivididas no tempo considerando nas parcelas quatro genótipos de laranjeira-doce $(14,48,51$ e 55) e nas subparcelas cinco épocas de maturação (116, 144, 172, 200 e 228 dias após o florescimento/antese) com três repetições. Não se verificou diferença entre as curvas de maturação dos genótipos para massa, comprimento e diâmetro dos frutos, ratio e rendimento de suco. Houve interação entre genótipos e tempo de avaliação para espessura de casca, ácido ascórbico, sólidos solúveis, acidez titulável e açúcares totais. Na última avaliação compararam-se os genótipos em relação ao índice tecnológico, número de sementes por fruto e produtividade, não sendo constatadas diferenças entre os mesmos. Apesar da diferença entre os genótipos para algumas variáveis, não foi encontrada diferentes curvas de maturação, não havendo diferença de época de maturação entre os genótipos 14, 48, 51 e 55, mas são promissores para um programa de melhoramento genético da espécie.

Termos de indexação: Citrus sinensis, laranja-doce, curva de maturação.

\section{Industrial quality and maturation of sweet orange fruits in Rio Branco, Acre}

\section{SUMMARY}

Although the orange tree is the second most cultivated fruit in the State of Acre, behind only the banana, production does not serve the local market, depending on the importation from other states, mainly due to the lack of genotypes adapted to the region. The objective of this work was to evaluate sweet orange genotypes, grafted on Cravo lemon, in relation to the production and physicochemical characteristics of the fruits at different maturation stages in Rio Branco, Acre. An experiment was carried out with a completely randomized design in split-plot arrangement, considering four plots of sweet orange $(14,48,51$ and 55) in the split-plots and

\footnotetext{
${ }^{1}$ Instituto Federal do Acre - IFAC, Rio Branco, AC, Brasil

${ }^{2}$ Empresa Brasileira de Pesquisa Agropecuária - Embrapa Acre, Rio Branco, AC, Brasil

${ }^{3}$ Universidade Federal do Acre - UFAC, Rio Branco, AC, Brasil

* Parte da dissertação do primeiro autor apresentada no PPG em Agronomia/Produção Vegetal da UFAC em 2013.

Autor correspondente: Virgínia de Souza Álvares, Empresa Brasileira de Pesquisa Agropecuária - Embrapa Acre, BR-364, Km 14, CEP 69900-970, Rio Branco, AC, Brasil. E-mail: virginia.alvares@embrapa.br
} 
five maturation seasons $(116,144,172,200$ and 228 days after flowering/anthesis) with three replicates. There was no difference between the maturity curves of the genotypes for fruit mass, length and diameter, juice yield and ratio. There was interaction between genotypes and time of evaluation for bark thickness, ascorbic acid, soluble solids, titratable acidity and total sugars. In the last evaluation, the genotypes were compared in relation to the technological index, number of seeds per fruit and productivity, and no differences were found between them. Despite the difference between the genotypes for some variables, different maturation curves were not found, with no maturation time difference between genotypes 14, 48, 51 and 55, but are promising for a breeding program of the species.

Index terms: Citrus sinensis, sweet orange, maturation curve.

\section{INTRODUÇÃO}

O Acre produziu, em 2015, aproximadamente 8,7 mil toneladas de laranjas (Citrus sinensis L. Osbeck) em uma área de 584 hectares e, apesar de ser a segunda frutífera mais cultivada no Estado, perdendo para a cultura da bananeira, e da produção ter aumentado em $56 \%$ nos últimos 10 anos (IBGE, 2017), a produção não atende o mercado local, dependendo da importação de outros Estados, principalmente de São Paulo (Gondim et al., 2001), cujo montante em 2011 foi de 423 toneladas (EMBRAPA, 2013). Mesmo não havendo limitação climática acredita-se que esta situação ocorra devido à falta de genótipos adaptados à região.

Embora existam pesquisas com variedades-copa e porta-enxertos no país, para o Acre estão recomendados para plantio apenas a laranja Aquiri com porta-enxerto citrange Carrizo (Citrus sinensis (L.), tangerina Cleópatra (Citrus reshni ex Hort. Tan.)e limoeiro Cravo (Citrus limonia Osb.) (Ledo et al., 1997a) e as laranjeiras Natal e Valência enxertadas em limoeiro Cravo (Ledo et al., 1997b).

Para selecionar plantas superiores e ampliar o número de variedades recomendadas para o Acre com épocas diversificadas de produção, expedições foram realizadas por Gondim et al. (2001) a alguns municípios do interior do Estado. Esta busca está fundamentada no fato de que o método mais rápido e eficaz de obter cultivares copas superiores refere-se à introdução e avaliação de germoplasmas, com posterior seleção das plantas com características desejáveis e que se adaptem aos sistemas de produção local (Lessa et al., 2009). Os genótipos selecionados estão sendo monitorados desde 2002. Embora os materiais ainda estejam em fase de avaliação na Embrapa Acre já existem resultados preliminares dos melhores genótipos em termos de produtividade. Porém a avaliação da qualidade dos frutos foi realizada em uma mesma época sem a consideração da sua precocidade ou não, o que pode ter alterado o resultado de características como teor de sólidos solúveis (açúcares) e acidez.

De acordo com Mattos Júnior et al. (1999) um dos primeiros procedimentos na caracterização de uma provável cultivar é a avaliação da curva de maturação, que será utilizada como critério de seleção dos materiais que atenderem as exigências locais. A curva de maturação é muito utilizada para separar grupos de cultivares com características físicas, químicas e, principalmente, época de produção diferente. Além disto, para a comercialização, a colheita dos frutos precisa ser realizada no estádio adequado de maturação, pois a laranja, por ser um fruto não-climatérico, não é capaz de completar o processo de amadurecimento fora da planta. Assim, o objetivo deste trabalho foi avaliar genótipos de laranjeira-doce, enxertadas sobre limoeiro Cravo, em relação à produção e características físico-químicas dos frutos em diferentes estádios de maturação em Rio Branco, Acre.

\section{MATERIAL E MÉTODOS}

O trabalho foi realizado em Rio Branco/AC $\left(10^{\circ} 1 \mathrm{~S}, 67^{\circ} 42 \mathrm{~W}\right.$, altitude de $\left.160 \mathrm{~m}\right)$. Utilizaram-se plantas de um ensaio de competição com 54 genótipos de laranjeira-doce, com 12 anos de idade mais a cultivar Aquiri enxertadas sobre limoeiro Cravo (Citrus limonia Osb.) da área experimental da Embrapa Acre. Para a formação do ensaio de campo, primeiramente estas plantas foram selecionadas de diversas regiões do Acre. Posteriormente, os genótipos foram selecionados por produtividade a partir do ensaio de competição existente, de acordo com observações de Lessa et al. (2009) e de Gondim et al. (2001) para estimativas das épocas de produção (precoce, meia-estação e tardia), sendo estas dos municípios de Senador Guiomard, Porto Acre e Rio Branco. Estas permaneceram com o mesmo código de campo dos 
trabalhos anteriores $(14,48,51$ e 55), sendo o último a cultivar Aquiri.

Do início do florescimento até o término das avaliações a precipitação pluvial acumulada foi de $1980 \mathrm{~mm}$, a temperatura média das máximas foi de $31,1{ }^{\circ} \mathrm{C}$ e das mínimas de $22,1^{\circ} \mathrm{C}$ e a umidade relativa média do ar foi de $87 \%$ (INMET, 2017).

De janeiro a maio de 2012, para cada genótipo, foram colhidos 12 frutos por planta, três de cada quadrante, a 1,5 metro de altura da copa, da parte externa da planta. Os frutos foram colhidos a cada 28 dias, do estádio de maturação completamente verde (116 dias) até excessivamente maduro (228 dias após o florescimento/antese). Estes foram avaliados quanto a: massa fresca dos frutos por meio de balança analítica digital, comprimento (medida do pedúnculo ao ápice do fruto), diâmetro (região equatorial) e espessura da casca (dois pontos opostos e equidistantes) com paquímetro digital, sólidos solúveis $\left({ }^{\circ}\right.$ Brix) por leitura direta em refratômetro digital, acidez por titulação com $\mathrm{NaOH}$ 0,1 N (AOAC, 2012), relação sólidos solúveis/acidez titulável (ratio), açúcares solúveis totais pelo método da antrona (Yemm \& Willis, 1954), ácido ascórbico por titulometria com solução de Tillman (Strohecker \& Henning, 1967), contagem direta do número de sementes e produtividade (caixas por planta). Ao final das avaliações calculou-se o rendimento do suco expresso em porcentagem [(massa do suco/massa dos frutos) $x$ 100] e o índice tecnológico [rendimento do suco x sólidos solúveis x 40,8 kg (massa padrão da caixa de colheita)/10.000].

Os dados obtidos foram analisados com auxílio do programa estatístico Sisvar ${ }^{\circledR}$ (Ferreira, 2008), sendo os resultados submetidos à análise de variância e comparação das médias pelo teste de Tukey a 5\% de probabilidade. Para os tempos obteve-se a regressão de maior grau significativo. No caso de interações significativas $(p<0,05)$ efetuou-se o desdobramento da análise de variância verificando-se o efeito dos genótipos dentro do tempo e vice-versa. Também se efetuou, pelo teste t de Student, a comparação das médias de algumas variáveis com valores de referência publicados.

O delineamento experimental foi o inteiramente casualizado (DIC) em parcelas subdivididas (4 x 5) no tempo sendo quatro genótipos $(14,48,51$ e 55$)$ nas parcelas, cinco estádios de maturação (116, 144, 172, 200 e 228 dias após o florescimento/antese) nas subparcelas e três repetições. Cada repetição correspondeu a uma planta.

\section{RESULTADOS E DISCUSSÃO}

Não se verificou interação significativa $(p>0,05)$ entre genótipos e período de avaliação para massa, comprimento e diâmetro dos frutos, ratio e rendimento de suco. A cultivar Aquiri e os genótipos foram selecionados de plantas locais, além de serem todas enxertadas no porta-enxerto limoeiro Cravo, o que pode explicar a ausência dessa interação.

As curvas de maturação dos frutos representadas por sua massa, comprimento e diâmetro, apresentaram comportamento quadrático (Figura 1), demonstrando a parte final da curva de crescimento e maturação dos frutos de laranjeira-doce conforme padrão sigmoidal, que, de acordo com Agustí et al. (1996), apresenta lento crescimento inicial e ao final as mudanças diretamente ligadas a maturação dos frutos. Além do padrão sigmoidal, a queda observada ao final da maturação para massa, comprimento e diâmetro pode ser explicada também pelo início da estiagem na região, pois, segundo Pozzan \& Triboni (2005), a massa do fruto está diretamente relacionada à disponibilidade hídrica do solo.

Os pontos de máximo foram atingidos em 194 dias após início do florescimento/antese com $203 \mathrm{~g} \mathrm{e} 73 \mathrm{~mm}$ de diâmetro e 209 dias com $71 \mathrm{~mm}$ de comprimento. Os frutos apresentaram massa média máxima superior às observadas por Auler et al. (2009), de 175,1 a 193,0 g, para laranja Valência sobre diferentes porta-enxertos, por Schinor et al. (2009), variando entre 88 e $149 \mathrm{~g}$ em dez seleções de laranja Pera e por Lemos et al. (2012), de 122,6 a 140,7 g, para laranja Pera em diferentes posições na copa. No entanto, para frutos de acessos da cultivar Seleta-Vermelha,

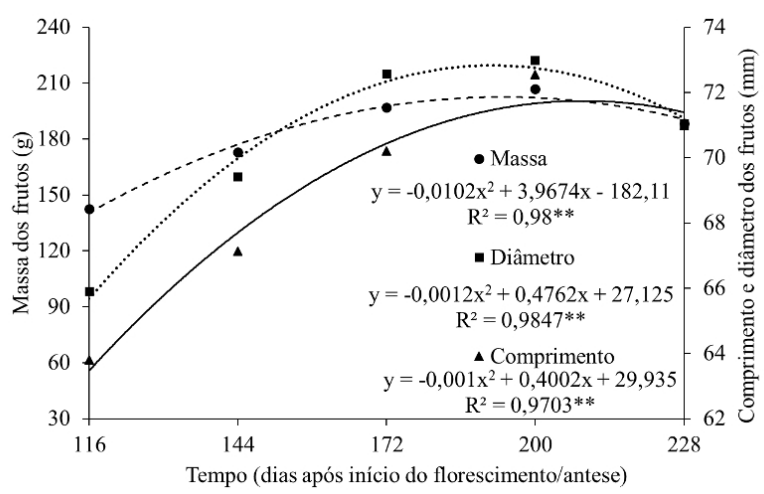

Figura 1. Massa, diâmetro e comprimento dos frutos de quatro genótipos de laranjeiras-doce durante período de maturação avaliados em Rio Branco-AC, 2012. ** Significativo à $1 \%$ de probabilidade. 
Tazima et al. (2009) obtiveram média de 208,7 g, similar à deste trabalho. Segundo Domingues et al. (2003) para atenderem os padrões de mercado as laranjas in natura devem apresentar comprimento e diâmetro médios acima de $70 \mathrm{~mm}$ e massa média de $152,5 \mathrm{~g}$, o que foi atingido aos 144 dias para diâmetro, 167 dias para comprimento e apenas 124 dias para massa dos frutos. Entretanto, nesta etapa os frutos ainda estavam verdes reafirmando a importância de avaliar os parâmetros físico-químicos para tomada de decisão do momento de colheita.

A espessura de casca apresentou interação significativa com diferenças entre os genótipos na terceira e quarta épocas de avaliação e menores valores para os genótipos 51 e 55 (Tabela 1) e comportamento linear decrescente (Figura 2).

Nos programas de melhoramento de laranja buscam-se frutos com menor espessura de casca, o que reflete diretamente no rendimento de suco e no melhor aproveitamento para a indústria. Entretanto, embora ocorreu redução dos

Tabela 1. Valores médios da espessura de casca $(\mathrm{mm})$ de quatro genótipos de laranjeiras-doce durante período de maturação avaliados em Rio Branco-AC, 2012

\begin{tabular}{cccccc}
\hline \multirow{2}{*}{ Genótipos } & \multicolumn{5}{c}{ Tempo } \\
& \multicolumn{5}{c}{ (dias após início do florescimento) } \\
\cline { 2 - 6 } & 116 & 144 & 172 & 200 & 228 \\
\hline 14 & $4,88 \mathrm{a}$ & $3,87 \mathrm{a}$ & $3,90 \mathrm{a}$ & $4,31 \mathrm{a}$ & $4,13 \mathrm{a}$ \\
48 & $4,84 \mathrm{a}$ & $3,77 \mathrm{a}$ & $3,37 \mathrm{ab}$ & $4,00 \mathrm{ab}$ & $3,60 \mathrm{a}$ \\
51 & $4,56 \mathrm{a}$ & $3,99 \mathrm{a}$ & $3,43 \mathrm{ab}$ & $3,18 \mathrm{c}$ & $3,58 \mathrm{a}$ \\
55 & $4,92 \mathrm{a}$ & $3,98 \mathrm{a}$ & $3,24 \mathrm{~b}$ & $3,36 \mathrm{bc}$ & $3,53 \mathrm{a}$ \\
\hline
\end{tabular}

Médias seguidas de mesma letra na coluna não diferem estatisticamente pelo teste de Tukey a 5\% de probabilidade.

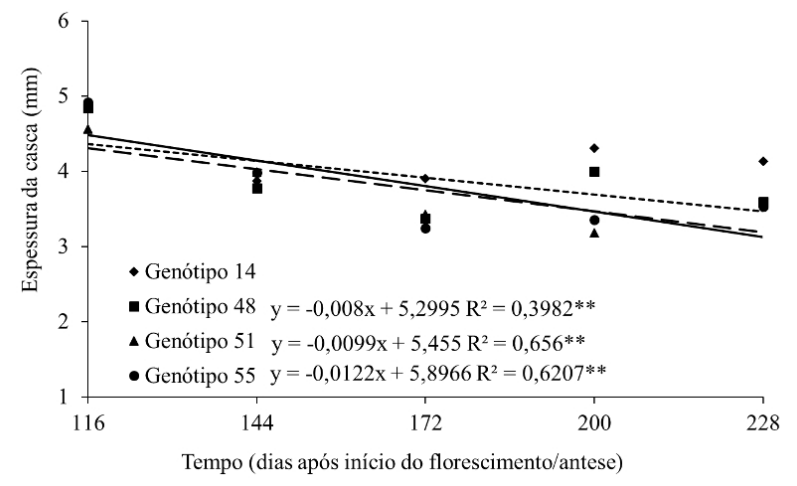

Figura 2. Espessura da casca dos frutos de quatro genótipos de laranjeiras-doce durante período de maturação avaliados em Rio Branco-AC, 2012. ** Significativo à $1 \%$ de probabilidade. valores desta variável ao longo do amadurecimento dos frutos (Figura 2) (com exceção do genótipo 14), na última avaliação todos apresentaram a mesma espessura de casca (Tabela 1), não havendo preferência entre os genótipos para esta variável.

O rendimento de suco variou de 35 a $45 \%$ entre a primeira e última avaliação, sendo estatisticamente igual ao obtido por Todisco et al. (2012) para a cultivar Folha Murcha e por Auler et al. (2009) para a laranjeira Valência. Entretanto, Sartori et al. (2002), estudando seis cultivares, obtiveram o rendimento de suco entre 50 e $60 \%$ e Stuchi et al. (2002) acima de 50\% para laranja Valência, sendo estes superiores aos observados neste trabalho. Mesmo estando abaixo de outras referências, o mínimo de $40 \%$ exigido pela indústria (Chitarra \& Chitarra, 2005) foi atingido para todas os genótipos avaliadas aos 151 dias.

Os sólidos solúveis dos frutos variaram de 7,00 a 9,98 ${ }^{\circ} \mathrm{Brix}$ (Tabela 2), com comportamento linear crescente para todos os genótipos (Figura 3). Este comportamento diferiu de Stenzel et al. (2006), que trabalhando com laranjeira Folha Murcha, em diferentes porta-enxertos, obtiveram ajuste quadrático da curva de regressão para esta variável. Auler et al. (2009), afirmam que a época de coleta tem efeito sobre a curva de maturação dos frutos encontrando diferentes ajustes de curva entre os anos avaliados, dependendo do padrão climático, cuja variação pode ser devida as oscilações de radiação solar (Lemos et al., 2012), luminosidade (Ramos et al., 2003), temperatura e chuva nas épocas-chave do ano, como o período da diferenciação e indução floral (Albrigo, 1992).

Alguns autores apresentam valores médios superiores do que os obtidos neste trabalho como Stenzel et al. (2006)

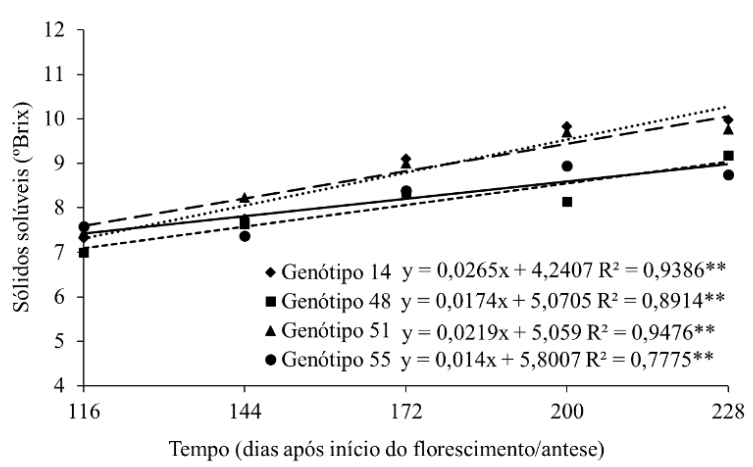

Figura 3. Sólidos solúveis ( ${ }^{\circ}$ Brix) no suco de frutos de quatro genótipos de laranjeiras-doce durante período de maturação avaliados em Rio Branco-AC, 2012. ** Significativo à $1 \%$ de probabilidade. 
para cultivar Folha Murcha $\left(10,12^{\circ}\right.$ Brix $)$, Auler et al. (2009) para cultivar Valência $\left(10,83^{\circ}\right.$ Brix) e Mattos Júnior et al. (1999) para diferentes laranjas-doce (10,7 ${ }^{\circ}$ Brix). Além disto, as médias encontradas não atingiram o mínimo (10,5 ${ }^{\circ}$ Brix) estabelecido pela Legislação Federal para sucos de laranja (Brasil, 2000). As quantidades relativas de sólidos solúveis, principalmente sacarose, glicose e frutose, oscilam dependendo da variedade, das condições climáticas e da localização da área de cultivo (Sugai et al., 2002). Sendo assim, os baixos valores de sólidos solúveis obtidos podem ser atribuídos ao excesso de chuva e dias nublados (ocorrência para essa época do ano no Acre), ocorrendo, segundo Albrigo (1992) e Auler et al. (2009), aumento dos teores de água nos frutos com diluição dos sólidos solúveis, ácidos e a diminuição da fotossíntese da planta.

$\mathrm{Na}$ comparação entre os materiais analisados, os genótipos 14 e 51 obtiveram os maiores valores de sólidos solúveis nas duas últimas avaliações, sendo que na última o genótipo 48 também se sobressaiu (Tabela 2). O genótipo 55, atual cultivar recomendada para o Acre, apresentou valores menores de sólidos solúveis que os demais avaliados, indicando serem estes promissores para um programa de melhoramento.

A acidez titulável decresceu em todos os genótipos durante seu amadurecimento (Figura 4) atingindo valores mínimos entre 217 e 222 dias após o início do florescimento/antese. O genótipo 55 (cultivar Aquiri) apresentou maior acidez nas quatro primeiras avaliações (Tabela 3), reforçando o potencial dos materiais estudados para a região.

Os autores Sartori et al. (2002) e Stenzel et al. (2006) também verificaram redução na acidez com a maturação, que, segundo Duarte et al. (2011), independe da carga remanescente dos frutos na planta. Esse comportamento ocorre devido à utilização dos ácidos orgânicos durante o processo respiratório ou de sua conversão em açúcares. A concentração diminui devido ao aumento do tamanho do fruto e do uso na respiração, dependente da temperatura que, segundo Albrigo (1992), quanto maior for durante a maturação, maior será o decréscimo da concentração dos ácidos. Frutos que recebem maior incidência de radiação solar têm diminuição no teor de acidez (Stenzel et al., 2006; Lemos et al., 2012). Essa situação pode explicar os baixos valores de ácido cítrico no suco uma vez que a temperatura local (Rio Branco, Acre) é alta, alcançando média das máximas de $31,1^{\circ} \mathrm{C}$. A temperatura do ar é a variável meteorológica que exerce maior efeito na taxa de maturação dos frutos (Volpe et al., 2002), alterando
Tabela 2. Valores médios de sólidos solúveis ( ${ }^{\circ}$ Brix) no suco de quatro genótipos de laranjeira-doce durante período de maturação avaliados em Rio Branco-AC, 2012 Tempo

\begin{tabular}{cccccc} 
Genótipos & \multicolumn{5}{c}{ (dias após início do florescimento) } \\
\cline { 2 - 6 } & 116 & 144 & 172 & 200 & 228 \\
\hline 14 & 7,32 a & 7,75 a & 9,10 a & 9,83 a & 9,98 a \\
48 & 7,00 a & 7,63 a & 8,35 a & 8,13 c & $9,18 \mathrm{ab}$ \\
51 & 7,43 a & 8,23 a & 9,00 a & 9,70 ab & 9,77 a \\
55 & 7,58 a & 7,37 a & 8,38 a & 8,95 bc & $8,75 \mathrm{~b}$ \\
\hline
\end{tabular}

Médias seguidas de mesma letra na coluna não diferem estatisticamente pelo teste de Tukey a $5 \%$ de probabilidade.

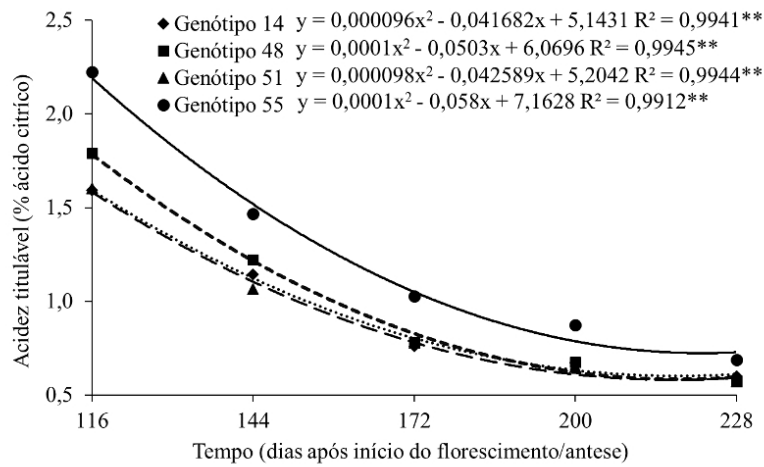

Figura 4. Acidez titulável no suco de frutos de quatro genótipos de laranjeiras-doce durante período de maturação avaliados em Rio Branco-AC, 2012. ** Significativo à $1 \%$ de probabilidade.

Tabela 3. Valores médios de acidez titulável (\% ácido cítrico) no suco de quatro genótipos de laranjeira-doce durante período de maturação avaliados em Rio Branco-AC, 2012

\begin{tabular}{cccccc}
\hline \multirow{2}{*}{ Genótipos } & \multicolumn{5}{c}{$\begin{array}{c}\text { Tempo (dias após início do } \\
\text { florescimento) }\end{array}$} \\
\cline { 2 - 6 } & 116 & 144 & 172 & 200 & 228 \\
\hline 14 & $1,59 \mathrm{c}$ & $1,14 \mathrm{bc}$ & $0,76 \mathrm{~b}$ & $0,67 \mathrm{~b}$ & $0,60 \mathrm{a}$ \\
48 & $1,79 \mathrm{~b}$ & $1,22 \mathrm{~b}$ & $0,78 \mathrm{~b}$ & $0,68 \mathrm{~b}$ & $0,58 \mathrm{a}$ \\
51 & $1,60 \mathrm{c}$ & $1,07 \mathrm{c}$ & $0,78 \mathrm{~b}$ & $0,65 \mathrm{~b}$ & $0,57 \mathrm{a}$ \\
55 & $2,22 \mathrm{a}$ & $1,47 \mathrm{a}$ & $1,03 \mathrm{a}$ & $0,87 \mathrm{a}$ & $0,69 \mathrm{a}$ \\
\hline
\end{tabular}

Médias seguidas de mesma letra na coluna não diferem estatisticamente pelo teste de Tukey a $5 \%$ de probabilidade.

o comportamento da variação dos sólidos solúveis e, principalmente, dos ácidos, causando mudanças no valor do ratio (relação sólidos solúveis/acidez titulável) (Volpe et al., 2000). 
A acidez variou de 2,22 a 0,57\% (Tabela 3). Blumer et al. (2003) avaliando laranjas de maturação tardia do Banco Ativo de Germoplasma do Centro APTA Citros "Sylvio Moreira" obtiveram, para 15 acessos, variações de 0,73 a 1,52\% para acidez, sendo todos os valores desta faixa superiores aos encontrados na última avaliação. A acidez da laranja não pode ser muito baixa, pois leva ao sabor insípido. Esse é o principal parâmetro de qualidade perceptível pelos consumidores e torna-se adequado para o consumo quando se situa de $0,9 \%$ a $0,6 \%$ (Pozzan \& Triboni, 2005). Os genótipos 14, 48 e 51 enquadraram-se nesta faixa a partir de 172 dias após o início do florescimento/antese. Entretanto, nesta fase os frutos ainda se encontravam com baixos valores de sólidos solúveis, indicando não estarem em ponto ideal de consumo. O genótipo 55 atingiu esses valores apenas aos 200 dias, indicando ser mais tardia em relação à esta característica, embora na última avaliação tenha se equiparado aos demais genótipos.

A relação sólidos solúveis/acidez titulável (ratio) aumentou ao longo do período de avaliação, iniciando em $4: 1$, atingindo o ponto ideal para consumo in natura de 12:1 (Di Giorgi et al., 1990) com 191 dias e alcançando ao final 15,8, que segundo Sartori et al. (2002), está próximo ao que deixaria o suco com sabor de "vencido" $(16,0)$. Desta forma, acredita-se que a colheita mais tardia prejudicaria a qualidade do produto neste aspecto. Obenland et al. (2009) concluíram que o padrão Califórnia 8:1 está muito abaixo do aceitável pelos provadores, sendo que o Ministério da Agricultura (Brasil, 2000) apresenta como um dos parâmetros mínimos de qualidade para o consumo de laranja comercial a faixa de 9,0 a 20,0. Já para Sartori et al. (2002), a faixa considerada adequada está entre 8,8 e 15,4. Entretanto, essa provável faixa ideal depende do destino da fruta. Segundo Pozzan \& Triboni (2005) a exigência da indústria é de 13:1, que neste trabalho foi atingido aos 200 dias após início do florescimento/antese. Para Couto \& Canniatti-Brazaca (2010), valores de ratio entre 12 e 13 são ideais para se iniciar o processamento industrial.

Os açúcares totais apresentaram comportamento quadrático e interação significativa $(p<0,05)$ entre os genótipos e os tempos de avaliação. Inicialmente os teores de açúcares aumentaram atingindo máximo aos 207 dias para o genótipo 14 e aos 183 dias para os demais genótipos $(48,51$ e 55$)$, com leve queda ao final da maturação (Figura 5). No início das avaliações os açúcares totais (Tabela 4) representavam aproximadamente $60 \%$ dos sólidos solúveis (Tabela 2). Esse valor aumentou até atingir seu máximo (80\%) na penúltima avaliação e caindo para próximo dos $60 \%$ na última avaliação.
As diferenças entre os genótipos para açúcares totais ocorreram na quarta e quinta avaliação (Tabela 4) onde se observaram maiores teores nos genótipos 14 e 51, sendo estas as mais indicadas para o programa de melhoramento com base nesta característica. Estes genótipos também possuíam os maiores valores de sólidos solúveis neste período de avaliação (Tabela 2).

Os teores de ácido ascórbico apresentaram interação significativa entre os genótipos e os tempos de avaliação com comportamento quadrático para os genótipos 14, 48 e 51 com leve queda na última análise e linear para o genótipo 55 (Figura 6). Os valores estiveram entre 128,02 e 104,73 mg $100 \mathrm{~g}^{-1}$ de suco e são superiores aos observados por Couto \& Canniatti-Brazaca (2010) de

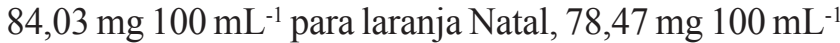
para laranja Valência e $80,03 \mathrm{mg} 100 \mathrm{~mL}^{-1}$ para laranja Bahia. Blumer et al. (2003) e Pozzan \& Triboni (2005)

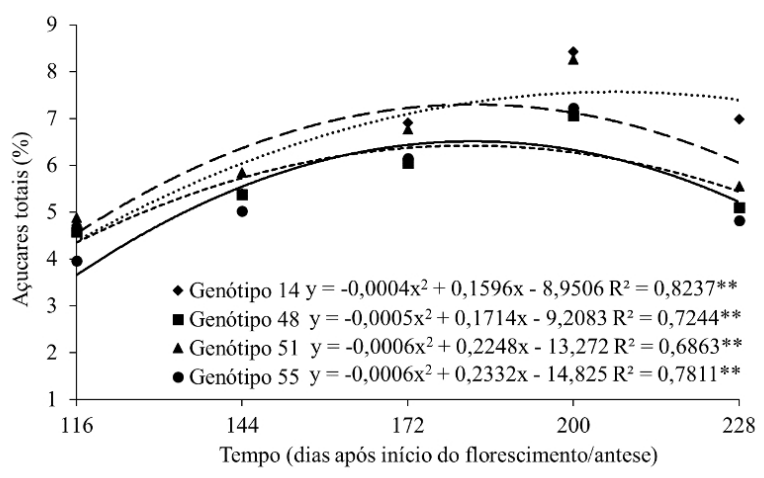

Figura 5. Açúcares totais no suco de frutos de quatro genótipos de laranjeiras-doce durante período de maturação avaliados em Rio Branco-AC, 2012. ** Significativo à $1 \%$ de probabilidade.

Tabela 4. Valores médios dos açúcares totais (\%) no suco de quatro genótipos de laranjeira-doce durante período de maturação avaliados em Rio Branco-AC, 2012

Tempo

Genótipos (dias após início do florescimento)

\begin{tabular}{cccccc} 
& 116 & 144 & 172 & 200 & 228 \\
\hline 14 & $4,72 \mathrm{a}$ & $5,41 \mathrm{a}$ & $6,91 \mathrm{a}$ & $8,43 \mathrm{a}$ & $6,99 \mathrm{a}$ \\
48 & $4,58 \mathrm{a}$ & $5,38 \mathrm{a}$ & $6,04 \mathrm{a}$ & $7,06 \mathrm{~b}$ & $5,10 \mathrm{~b}$ \\
51 & $4,88 \mathrm{a}$ & $5,84 \mathrm{a}$ & $6,76 \mathrm{a}$ & $8,26 \mathrm{a}$ & $5,56 \mathrm{~b}$ \\
55 & $3,96 \mathrm{a}$ & $5,03 \mathrm{a}$ & $6,15 \mathrm{a}$ & $7,22 \mathrm{~b}$ & $4,82 \mathrm{~b}$ \\
\hline
\end{tabular}

Médias seguidas de mesma letra na coluna não diferem estatisticamente pelo teste de Tukey a 5\% de probabilidade. 


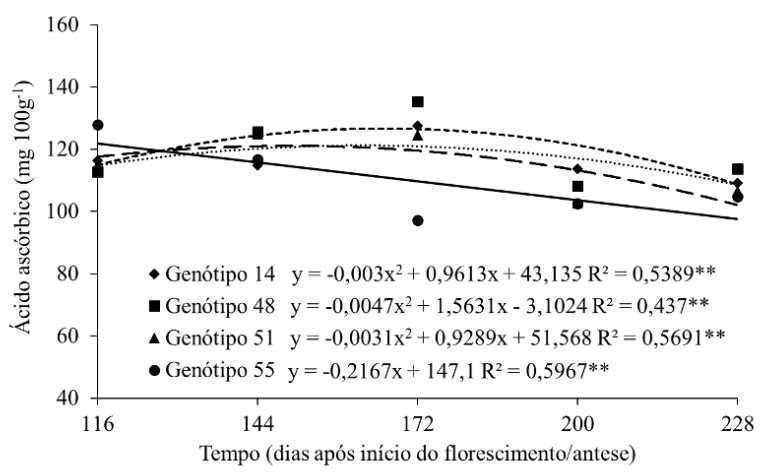

Figura 6. Ácido ascórbico no suco de frutos de quatro genótipos de laranjeiras-doce durante período de maturação avaliados em Rio Branco-AC, 2012. ** Significativo à $1 \%$ de probabilidade.

também verificaram redução no teor da vitamina $\mathrm{C}$ com a maturação dos frutos.

Quanto ao índice tecnológico (média de 1,70), produtividade (média de 3,35 caixa de $40,8 \mathrm{~kg}$ por planta) e o número de sementes por fruto (média de 12 sementes) não se verificaram diferenças entre os genótipos comparadas apenas na última avaliação. $\mathrm{O}$ índice tecnológico médio obtido foi inferior aos reportados por Stuchi et al. (2002) e Tazima et al. (2008) para a cultivar Valência, com média de 2,85 e 2,16, respectivamente, além de inferior ao máximo obtido por Auler et al. (2009), de 2,10, e por Blumer et al. (2003), de 2,52 a 2,73, para cultivares de maturação tardia. Este fato deve-se à combinação de baixos valores de sólidos solúveis e rendimento de suco encontrados neste trabalho, provavelmente, devido à época com excesso de chuvas e dias nublados da região Amazônica. O índice tecnológico é uma variável importante para indústria de suco concentrado e muito utilizado na escolha de cultivares promissoras para essa finalidade, mas não houve diferenciação dos genótipos neste aspecto.

Com relação ao número médio de sementes por fruto (12), o valor é considerado alto, pois de acordo com Latado et al. (2001), a obtenção de cultivares de laranja com baixo número de sementes é importante quando o objetivo é a produção de frutas para consumo in natura. Além disto, as sementes em desenvolvimento são uns dos principais locais de síntese de giberelina, hormônio inibidor da floração nos citros (Guardiola et al., 1982). Assim, a alta produção de sementes por planta poderia explicar a menor floração na safra seguinte (Duarte et al., 2011), o que pode interferir, inclusive, na produtividade e alternância de produção.
Apesar de haver diferenças entre os genótipos para algumas variáveis, essas não foram suficientes para classificá-las como precoces ou tardias apresentando o mesmo período de maturação. O limoeiro Cravo é o porta-enxerto mais utilizado por conferir maior vigor, produtividade e longevidade às copas e o fato de todas estarem sobre este porta-enxerto pode ter influência sobre a homogeneidade de maturação observada entre os genótipos pois, segundo Mattos Júnior et al. (2005), dentre as características influenciadas pelo porta-enxerto pode-se citar o período de maturação, produtividade, qualidade dos frutos, resistência à pragas e doenças e tolerância a condições desfavoráveis de solo e clima. Os porta-enxertos podem alterar o padrão de desenvolvimento da copa e interferir em processos fisiológicos como a fotossíntese.

O uso do mesmo porta-enxerto para todos os genótipos pode também explicar a equivalência de produtividade entre os genótipos. Porém os valores obtidos (3,35 caixas de 40,8 kg por planta) foram superiores às médias citadas por Andrade et al. (2002) da produtividade paulista ( 2,0 caixas), iguais a média paranaense $(3,0$ caixas) e inferiores à média da Flórida (EUA) de 6,0 caixas planta $^{-1}$ ano $^{-1}$.

\section{CONCLUSÕES}

Nas condições de Rio Branco, Acre, não há diferença na época de colheita entre os genótipos 14, 48, 51 e 55 (cultivar Aquiri) de laranjeira-doce.

Os genótipos 14, 48, 51 e 55 possuem características adequadas para o consumo in natura a partir dos 200 dias após o início do florescimento/antese, quando estas apresentam frutos maiores, maiores teores de sólidos solúveis, baixa acidez e elevado ratio.

Os genótipos apresentam produção à meia-estação e possuem potencial promissor para indústria e consumo in natura, a fim de dar continuidade ao programa de melhoramento genético de citros na região.

\section{AGRADECIMENTOS}

À Coordenação de Aperfeiçoamento de Pessoal de Nível Superior (CAPES) pela bolsa de estudos, à Universidade Federal do Acre (UFAC) pela concessão do Mestrado, à Empresa Brasileira de Pesquisa Agropecuária (Embrapa Acre) pelo desenvolvimento da pesquisa. 


\section{REFERÊNCIAS}

Agustí, M., Almela, V., Aznar, M., Juan, M., \& Peres, V. (1996). Citros: desenvolvimento e tamanho final do fruto (102 pp.). Porto Alegre: Ivo Mânica.

Albrigo, G. (1992) Influências ambientais no desenvolvimento dos frutos cítricos. In Anais II Seminário Internacional de Citros: Fisiologia (p. 100-106). Campinas: Fundação Cargill.

Andrade, R. S. G., Diniz, M. C. T., Neves, E. A., \& Nóbrega, J. A. (2002). Determinação e distribuição de ácido ascórbico em três frutos tropicais. Eclética Química, 27, 393-401.

Association of Official Analytical Chemists - AOAC. (2012). Official methods of analysis (19th ed.). Arlington: AOAC.

Auler, P. A. M., Fiori-Tutida, A. C. G., \& Scholz, M. B. S. (2009). Qualidade industrial e maturação de Frutos de Laranjeira Valência sobre seis porta-enxertos. Revista Brasileira de Fruticultura, 31, 1158-1167.

Blumer, S., Pompeu Junior, J., \& Garcia, V. X. P. (2003). Características de qualidade dos frutos de laranjas de maturação tardia. Laranja, 24, 423-431.

Brasil. Ministério da Agricultura, Pecuária e Abastecimento. (2000). Instrução Normativa $n^{\circ} 1$, de 7 de Janeiro de 2000. Regulamento técnico geral para fixação dos padrões de identidade e qualidade para polpa de fruta. Diário Oficial da República Federativa do Brasil, Brasília, DF, 10 jan. 2000. Recuperado em 26 de março de 2013, de http://extranet. agricultura.gov.br/sislegis-consulta/consultarlegislacao. do? operacao $=$ visualizar\& $\mathrm{Id}=7777$

Chitarra, M. I. F., \& Chitarra, A. B. (2005). Pós-colheita de frutas e hortaliças: fisiologia e manuseio (2. ed., 783 pp.) Lavras: UFLA.

Couto, M. A. L., \& Canniatti-Brazaca, S. G. (2010). Quantificação de vitamina C e capacidade antioxidante de variedades cítricas. Food Science and Technology, 30, 15-19.

Di Giorgi, F., Ide, B. Y., Dib, K., Marchi, R. J., Trioni, H. R., \& Wagner, R. L. (1990). Contribuição ao estudo do comportamento de algumas variedades de citros e suas implicações agroindustriais. Laranja, 11, 567-612.

Domingues, E. T., Tulmann Neto, A., Pompeu Junior, J., Teófilo Sobrinho, J., Mattos Junior, D., \& Figueiredo, J. O. (2003). Seleção de variedades de laranja quanto à qualidade do fruto e período de maturação. Laranja, 24, 471-470.

Duarte, T. F., Bron, I. U., Ribeiro, R. V., Machado, E. C., Mazzafera, P., \& Shimizu, M. M. (2011). Efeito da carga pendente na qualidade de frutos de laranjeira Valência. Revista Brasileira de Fruticultura, 33(3), 823-829.

Empresa Brasileira de Pesquisa Agropecuária-EMBRAPA \& Federação de Agricultura e Pecuária do Estado do Acre - FAEAC. (2013). Boletim de preços de produtos agropecuários e florestais do Estado do Acre (8. ed., 5 p., Ano 2). Rio Branco: Embrapa/Faeac.

Ferreira, D. F. (2008). SISVAR: um programa para análises e ensino de estatística. Revista Symposium, 6(2), 36-41.

Gondim, T. M. S., Rtzinger, R., \& Cunha Sobrinho, A. P. C. (2001). Seleção e caracterização de laranjeiras-doces (Citrus Sinensis (L.) Osbeck) no Estado do Acre. Revista Brasileira de Fruticultura, 23, 451-454.

Guardiola, L. L., Monerri, C., \& Agusti, M. (1982). The inhibitory effect of gibberelic acid on flowering in Citrus. Physiologia Plantarum, 55(2), 136-142.

Instituto Brasileiro de Geografia e Estatística - IBGE. (2017). Sistema IBGE de recuperação automática - Sidra. Recuperado em 21 de fevereiro de 2017, de https://sidra. ibge.gov.br/tabela/1613\#

Instituto Nacional de Meteorologia - INMET. (2017). Banco de Dados Meteorológicos para Ensino e Pesquisa do Instituto Nacional de Meteorologia. Recuperado em 12 de julho de 2017, de http://www.inmet.gov.br/projetos/ rede/pesquisa/

Latado, R. R., Tulmann Neto, A., Ando, A., Iemma, A. F., Pompeu Junior, J., Figueiredo, J. O., Pio, R. M., Machado, M. A., Namekata, T., Ceravolo, L., \& Rossi, A. C. (2001). Mutantes de Laranja-Pêra com número reduzido de sementes obtidos através de mutações induzidas. Revista Brasileira de Fruticultura, 23, 339-344.

Ledo, A. S., Ledo, F. J. S., Ritzinger, R., Pimentel, F. A., \& Azevedo, F. F. (1997a). Recomendações da laranja Aquiri e técnicas para o plantio no Estado do Acre (Comunicado Técnico, 73, 4 p.,). Rio Branco: Embrapa Acre.

Ledo, A. S., Ledo, F. J. S., Ritzinger, R., Pimentel, F. A., \& Azevedo, F. F. (1997b). Recomendações das laranjas natal e valência e técnicas para o plantio no Estado do Acre (Comunicado Técnico, 75, 4 p.,). Rio Branco: Embrapa Acre. 
Lemos, L. M. C., Siqueira, D. L., Salomão, L. C. C., Cecon, P. R., \& Lemos, J. P. (2012). Características físico-químicas da Laranja-Pera em função da posição na copa. Revista Brasileira de Fruticultura, 34, 1091-1097.

Lessa, L. S., Roncatto, G., Oliveira, T. K., Negreiros, J. R. S., Álvares, V. S., Siviero, A., \& Maia, M. C. C. (2009) Seleção de clones de laranjeiras-doces com base em índices não-paramétricos. In Anais $V$ Congresso Brasileiro de Melhoramento de Plantas. Vitória: SBMP: Incaper. 1 CD-ROM.

Mattos Júnior, D., De Negri, J. D., Pio, R. M., \& Pompeu Junior, J. (Org.) (2005) Citros (Vol. 1, 929 pp.). Campinas: Instituto Agronômico e Fapesp.

Mattos Júnior, D., Gonzales, A. F., Pompeu Junior, J., \& Parazzi, C. (1999). Avaliação de curvas de maturação de laranjas por análise de agrupamento. Pesquisa Agropecuária Brasileira, 34, 2203-2209.

Obenland, D., Collin, S., Mackey, B., Sievert, J., Fjeld, K., \& Arpaia, M. L. (2009). Determinants of flavor acceptability during the maturation of navel oranges. Postharvest Biology and Technology, 52, 156-163.

Pozzan, M., \& Triboni, H. R. (2005) Colheita e qualidade do fruto. In D. Mattos Junior, J. D. De Negri, R. M. Pio, \& J. Pompeu Junior (Eds.), Citros (p. 801-822). Campinas: Instituto Agronômico de Campinas.

Ramos, J. D., Carrijo, E. P., Pio, R., Gontijo, T. C. A., \& Coelho, J. H. C. (2003). Características físico-químicas de frutos de Mexerica-do-Rio em função da disposição geográfica e altura de inserção na planta. Revista Científica Rural, 8(2), 87-91.

Sartori, I. A., Koller, O. C., Schwarz, S. F., Bender, R. J., \& Schäfer, G. (2002). Maturação de frutos de seis cultivares de laranjas-doces na depressão central do Rio Grande do Sul. Revista Brasileira de Fruticultura, 24, 364-369.

Schinor, E. H., Aguilar-Vildoso, C. I., \& Mourão Filho, F. A. A. (2009). Caracterização agronômica de seleções de laranjeira Pera e sua relação com a mancha-preta dos citros. Laranja, 30(1-2), 75-96.

Stenzel, N. M. C., Neves, C. S. V. J., Marur, C. J., Scholz, M. B. S., \& Gomes, J. C. (2006). Maturation curves and degree-days accumulation for fruits of Folha Murcha orange trees. Scientia Agrícola, 63, 219-225.
Strohecker, R., \& Henning, H. M. (1967). Analisis de vitaminas: métodos comprovados (428 pp.). Madrid: Paz Montalvo.

Stuchi, E. S., Donadio, L. C., \& Sempionato, O. R. (2002). Qualidade industrial e produção de frutos de laranjeira valência enxertada sobre sete porta-enxertos. Laranja, 23, 453-471.

Sugai, A. Y., Shigeoka, D. S., Badolato, G. G., \& Tadini, C. C. (2002). Análise físico-química e microbiológica do suco de laranja minimamente processado armazenado em lata de alumínio. Revista Ciência e Tecnologia de Alimentos, 22, 233-238.

Tazima, Z. H., Auler, P. A. M., Neves, C. S. V. J., Yada, I. F. U., \& Leite Junior, R. P. (2008). Comportamento de clones de laranja Valência na região Norte do Paraná. Revista Brasileira de Fruticultura, 30(4), 970-974.

Tazima, Z. H., Neves, C. S. V. J., Stenzel, N. M. C., Yada, I. F. U., \& Leite Junior, R. P. (2009). Produção e qualidade de frutos de cultivares de laranja-doce no norte do Paraná. Revista Brasileira de Fruticultura, 31, 474-479.

Todisco, K. M., Clemente, E., \& Rosa, C. I. L. F. (2012). Conservação e qualidade pós-colheita de laranjas Folha Murcha armazenadas em duas temperaturas. Revista em Agronegócio e Meio Ambiente, 5, 579-591.

Volpe, C. A., Schöffel, E. R., \& Barbosa, J. C. (2000). Influência de algumas variáveis meteorológicas sobre a qualidade dos frutos de laranjeiras-Valência e Natal. Revista Brasileira de Agrometeorologia, 8(1), 85-94.

Volpe, C. A., Schöffel, E. R., \& Barbosa, J. C. (2002). Influência da soma térmica e da chuva durante o desenvolvimento de laranjas-Valência e Natal na relação entre sólidos solúveis e acidez e no índice tecnológico do suco. Revista Brasileira de Fruticultura, 24(2), 436-441.

Yemm, E. W., \& Willis, A. J. (1954). The estimation of carbohydrate in plant extracts by anthrone. The Biochemical Journal, 1, 508-522.

Recebido: Março 13, 2017

Aceito: Junho 10, 2017

Como citar: Beber, P. M., Álvares, V. S., \& Kusdra, J. F. (2018). Qualidade industrial e maturação de frutos de laranjeiras-doce em Rio Branco, Acre. Citrus Research and Technology, 39, e-1030. http://dx.doi.org/10.4322/crt.10317 